\title{
Seismic Vulnerability Assessment Using Rapid Visual Screening: Case Study of Educational Facility Buildings of Jenderal Soedirman University, Indonesia
}

\author{
Haryanto, Y., 1,2*, Hu, H.-T.1, Han, A.L. ${ }^{3}$, Hidayat, B.A.', Widyaningrum, A. ${ }^{2}$, and \\ Yulianita, P.E. ${ }^{2}$
}

\begin{abstract}
Recent earthquake activity has brought about extensive structural damage and loss of life. The adverse effects of earthquakes on the economic sector can be seen all over the world, particularly in developing countries. This calls for those developing countries to adhere to various methods to combat these effects. Buildings serving the educational needs of the people can also contribute by accommodating people in case of emergencies and disaster. Therefore, these buildings must be evaluated in terms of their capacity and strength in the face of earthquakes. This study will employ the Rapid Visual Screening (RVS) technique to evaluate the seismic vulnerability condition of nine reinforced concrete educational buildings at Jenderal Soedirman University, Indonesia, five located in Purbalingga, and four in Purwokerto. The results of the study allow the authorities concerned to devise a prioritization plan regarding the structural safety of all of the educational buildings at Jenderal Soedirman University, Indonesia.
\end{abstract}

Keywords: Earthquake; educational buildings; Rapid Visual Screening; seismic vulnerability assessment.

\section{Introduction}

Seismic vulnerability evaluation is an accepted technique for the evaluation of buildings to determine if they are capable of accomplishing specific performance objectives. The technique identifies the buildings' divergence from the standards required to achieve their performance objective. The main objectives of seismic vulnerability evaluation are explained in what follows. Some existing buildings may have not been designed in accordance with the current seismic codes, having been constructed before the codes were drawn up, and may therefore not be strong enough to resist seismic forces. Moreover, a building may have suffered wear and tear over the years, or its condition may have declined due to a change of use or the high liquefaction potential of the land. The results obtained from seismic evaluation will be used to determine if the building needs repairs or renovation to enhance its resistance against seismic forces or if it needs instead to be demolished [1,2].

${ }^{1}$ Department of Civil Engineering, National Cheng Kung University, 1 University Road, Tainan, Taiwan, 701, TAIWAN

2 Department of Civil Engineering, Jenderal Soedirman University, Jln. Mayjen. Sungkono KM 5, Blater, Purbalingga 53371, INDONESIA

${ }^{3}$ Department of Civil Engineering, Diponegoro University, Jn. Prof. Soedarto, Tembalang, Semarang 50275, INDONESIA

* Corresponding author; email: yanuar.haryanto@unsoed.ac.id

Note: Discussion is expected before July, $1^{\text {st }} 2020$, and will be published in the "Civil Engineering Dimension", volume 22, number 2, September 2020.

Received 06 November 2019; revised 04 April 2020; accepted 25 April 2020
The seismic risk and the structural weakness of a building determine if the building is vulnerable to earthquakes. Seismic hazard evaluation is associated with the facts about the probability of a location being struck by an earthquake of a specific intensity or magnitude. The risk includes the probable loss of lives and structures that may occur as a consequence of the earthquake in a specific area at a specific time. It is computed as the product of hazard and vulnerability [3]. A structure or building is said to be vulnerable to seismic forces if there is a probability of the structure or its foundations, pillars or floors being damaged by the earthquake [2].

Seismic vulnerability evaluation considers various aspects of a building to determine its vulnerability. It considers both the building's design and wear and tear it has suffered [1]. If a building or structure is not resistant to seismic forces, it is said to be vulnerable. This implies the seismic deficiency of the structure, which is described as the building's failure to fulfil the required performance objective. An identified deficiencies may show different outcomes for a particular building assessed for immediate occupancy or as for life safety. The objectives of providing immediate occupancy (full occupancy immediately after an event) will have higher requirements from the building as compared to life saving objectives. The life safety performance level indicates that, despite the probable damage that may be caused to the building's structure, it will still not experience total structural collapse, whereas immediate occupancy performance indicates that the building will not experience any significant damage to structural and non-structural parts. 


\section{Rapid Visual Screening}

Despite the vulnerability of Indonesia to seismic forces, most of the buildings in this part of the world are not resistant to seismic forces and are thus exposed to risk. Indonesia has been a frequent victim of seismic forces and earthquakes. Data show that it has experienced almost $10 \%$ of the total earthquakes worldwide, with an average of ten destructive earthquakes occurring in the region every year. These have caused numerous losses to the region in terms of lives and structural damage resulting from tsunamis, land liquefaction, and other adversities [4]. This study aims to allow concerned authorities to devise a prioritization plan for preparing the nine educational buildings of the Jenderal Soedirman University, Purbalingga, Indonesia, in such a way as to enhance their seismic performance so that they can effectively serve people in the event of an earthquake by both saving lives and accommodating people during the incident.

Seismic vulnerability evaluation may be performed through various techniques, of which the most prominent is Rapid Visual Screening (RVS). This technique does not require any structural measurements but involves conducting a visual survey from the pavement and consequently entering the collected data in a form [5,6]. This technique enables the authorities to identify and prioritize areas that need attention and to propose improvements in those areas. This technique also allows surveys to be customized according to the requirements [7], as in the case of India, where this technique was applied to stone buildings and concrete buildings to evaluate them independently for five different seismic regions [8,9]. Japanese buildings have been evaluated through surveys that assess the buildings' seismic index (strength, flexibility and regularity) [10], while Canadian buildings are assessed with respect to both structural parameters (stiffness and regularity) and nonstructural parameters (occupancy and danger of collapsing) [11].

RVS is widely employed all around the world. The RVS technique was used to assess 375 ancient stone buildings in Vienna by taking into account the buildings' degree of damage and structural parameters. This allowed the authorities to detect the factors responsible for seismic vulnerability [12]. RVS was also used to assess buildings having more than 5 floors in Chennai with the help of aerial images employed in a GIS platform [13]. Moseley and Dritsos integrated Fuzzy logic in the RVS technique [14]. In India, an RVS assessment of existing buildings was conducted through a statistical analysis [15]. The RVS technique was recently developed further to offer an additional risk index parameter which is determined by the assessment of the factors identified as having an effect on the vulnerability of buildings during the pavement visual survey. This new technique was used in a couple of hospitals in Italy [16].
Figure 1 shows the order of the steps involved in applying the RVS technique [5]. An account of the project scope and budget is followed by the application of this technique with the following pre-field procedures:

1. The foremost step is pre-field planning, which involves the selection of a proper record-keeping system and development of automated scoring systems (if needed). It also involves collecting various maps that show local seismic data and highlight vulnerable regions;

2. A data collection form to supports relevant assessment of seismic vulnerability is selected. This is followed by adjustment of the form according to the specific requirements of the RVS program;

3. The evaluation personnel are selected and appropriately trained;

4. The pre-field data is collected and evaluated. This involves collecting data pertaining to the buildings being evaluated and the consequent assessment of that data to reveal various details about the buildings such as their location, building identification number (BIN), date of design and number of floors. Moreover, the available data is also evaluated to determine the soil type of the land on which the building stands;

5. The currently available building plans are reviewed.

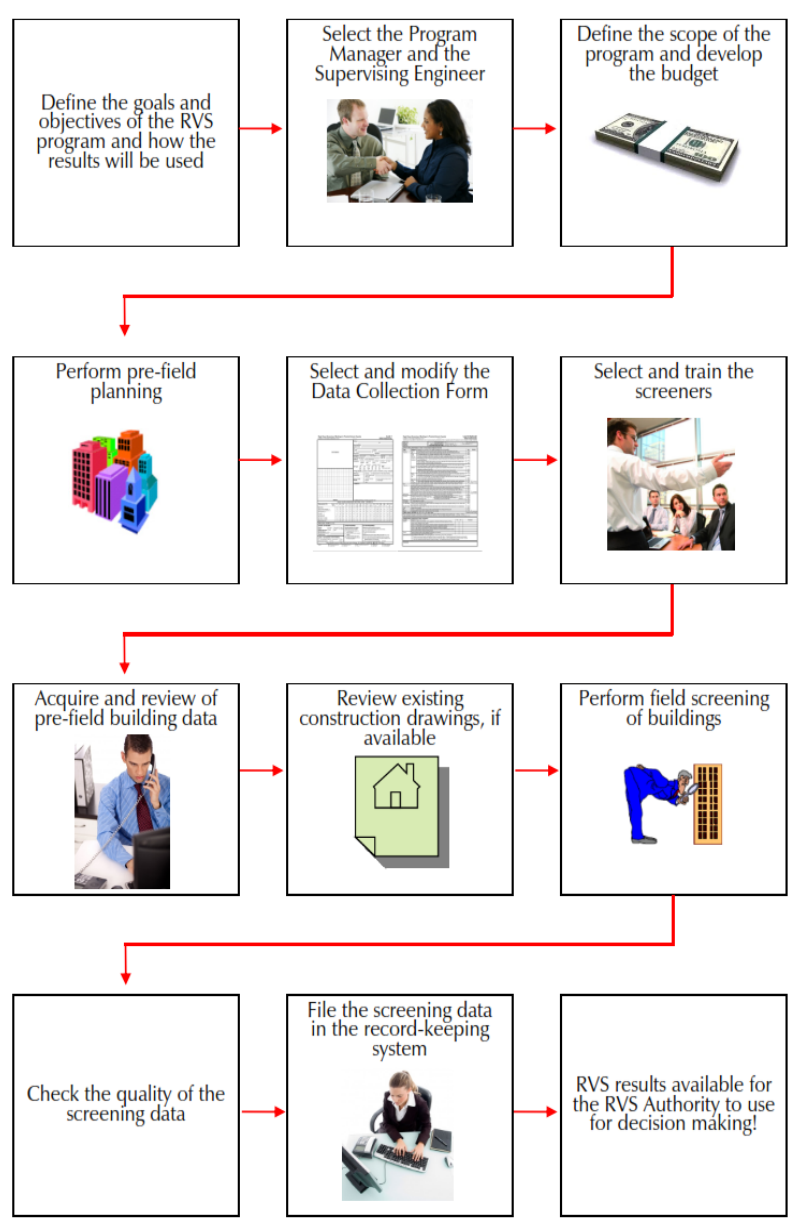

Figure 1. RVS Implementation Sequence [5] 
Rapid Visual Screening of Buildings for Potential Seismic Hazards FEMA P-154 Data Collection Form

Level 1

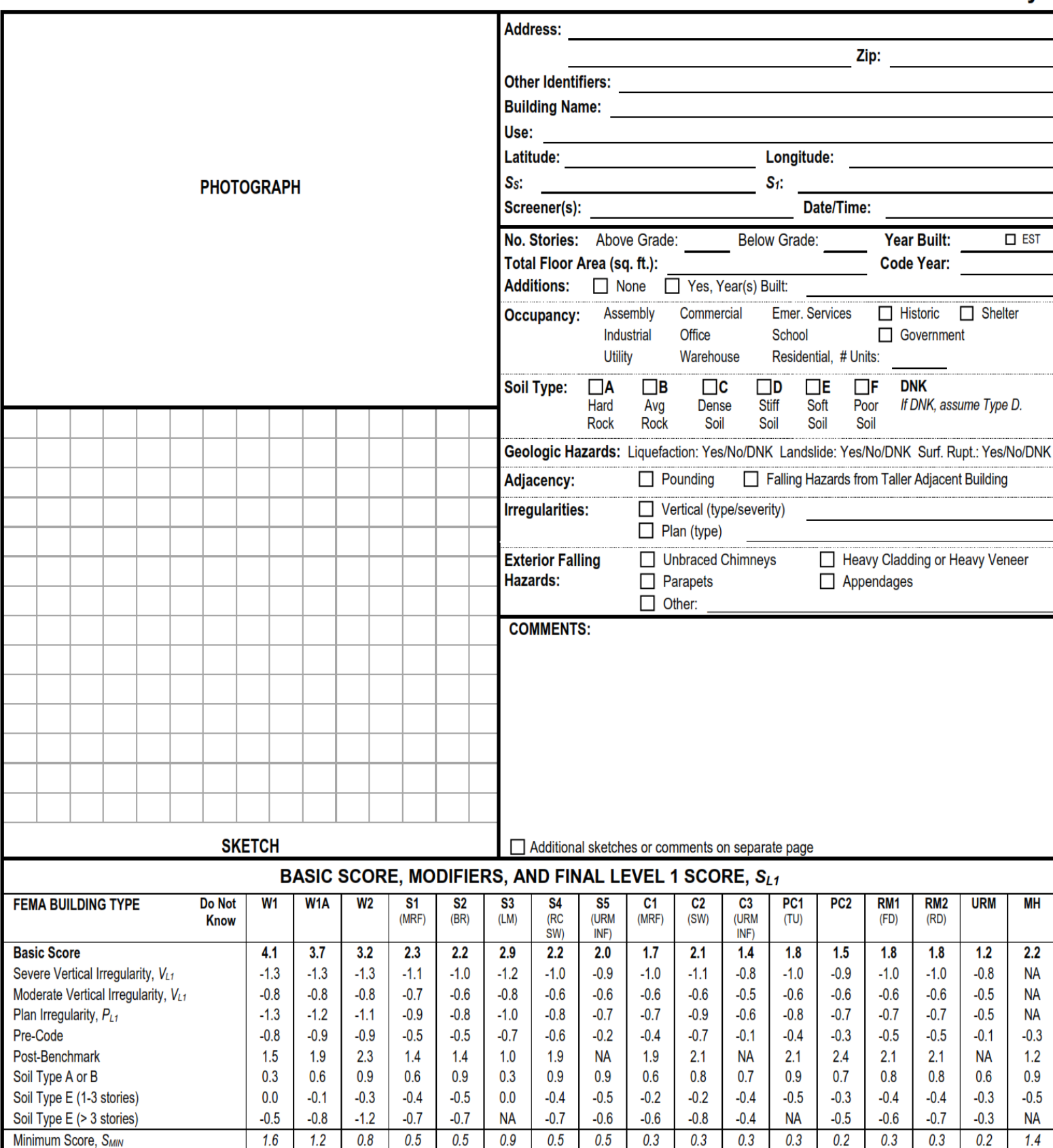

FINAL LEVEL 1 SCORE, SL1 $\geq$ SMIN:

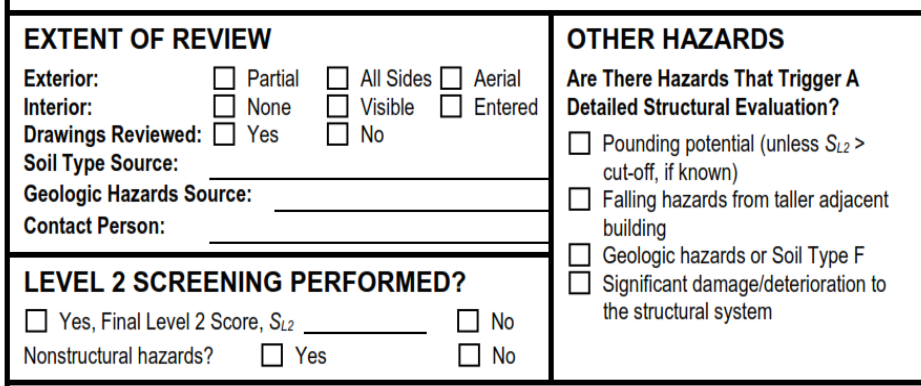

ACTION REQUIRED

Detailed Structural Evaluation Required?

$\square$ Yes, unknown FEMA building type or other building

Yes, score less than cut-off

Yes, other hazards present

$\square$ No

Detailed Nonstructural Evaluation Recommended? (check one)

$\square$ Yes, nonstructural hazards identified that should be evaluated

$\square$ No, nonstructural hazards exist that may require mitigation, but a

detailed evaluation is not necessary

$\square$ No, no nonstructural hazards identified $\square$ DNK

Where information cannot be verified, screener shall note the following: EST = Estimated or unreliable data $\underline{O R} \quad$ DNK $=$ Do Not Know

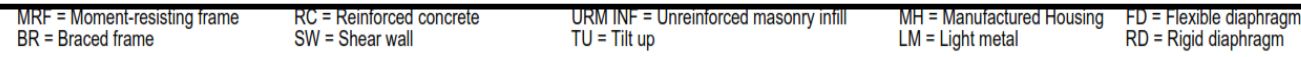

Figure 2. The Level 1 Data Collection Form 
Figure 2 shows the Level 1 Data Collection Form developed on the basis of FEMA P-154 [5]. The following steps are taken to fill in this form for all the buildings being evaluated:

1. The building's identification information is confirmed and inserted in the forms;

2. The building is examined visually by walking around it to determine the structure and number of floors and making a sketch of its elevation and structure in the Data Collection Form;

3. Taking images and pictures of the building;

4. The building's occupancy is determined and noted down in the form;

5. The soil type and geologic risks that were found in the pre-field planning process are once again viewed at this point;

6. The issues associated with adjacency, building defects, and the expected risk of collapse of the structure are determined;

7. Further comments may be added to the form, mentioning any factors that are likely to influence the evaluation outcomes;

8. The material used in the construction of the building, its gravity load-carrying system and its force-resisting system are all checked to determine the FEMA building type. It is best to enter the building to obtain all this information. This is followed by computing the basic score on the basis of this information and inserting it in the Data Collection Form;

9. The appropriate Score Modifiers related to the attributes that affect the seismic performance of buildings (such as defects, design date, and soil type) are circled on the Data Collection Form;

10. The calculated basic score is adjusted to the score modifiers to come up with the Final Level 1 Score denoted by $S_{L 1}$;

11. The last part of the form is a summary section in which to specify any research reviews, other associated risks and essential actions.

\section{Building Occupancy}

Building occupancy means the use or operations of the building. Although the structural risks and damage sustenance are not directly related to building occupancy, this factor is significant when it comes to the establishment of priorities for addressing these issues.

1. Occupancy Classes

Figure 2 explains the nine classes of occupancy devised for the purpose of simply identifying the building occupancy during RVS. The classes have been devised based on easily observable and apparent characteristics that allow easy distinctions to be made between buildings. These classes are given below:
- Assembly. Buildings designated for the assembly of large groups of people and to accommodate a large crowd at the same time. Building codes suggest accommodating a minimum of 300 people to be designated an assembly. The same code will be adopted in this study. Places of assembly include cinemas, halls, community centers, theaters, and places of worship.

- Commercial. Any building accommodating a retail or wholesale enterprise, restaurants, and banks come under this category.

- Emergency Services. These include all buildings that serve as a shelter in case of disasters and emergency situations. Examples of such buildings are police stations, fire stations, hospitals and even some educational facilities.

- Industrial. These are buildings that house industrial units like factories and manufacturing plants and assembly plants.

- Office. These buildings house service centers that involve office work like clerical, managerial and professional services.

- Residential. All kinds of residences and accommodation are included in this class, including bungalows, apartments, hotels, old people's homes, orphanages. It is important to specify in the form the number of residential units in each building.

- School. This class includes all buildings housing educational institutes of primary, secondary and tertiary levels, whether public or private.

- Utility. This includes all buildings that are occupied by public or private utilities including power plants, electricity plants, and watertreatment plants.

- Warehouse. This includes buildings serving the purpose of warehouse activities like the storage of goods and their sale.

The evaluator or screener must determine the class of occupancy on the basis of the above-mentioned information and then circle the corresponding option in the form. If a building serves multiple purposes, then all relevant classes must be circled. The form also has a section on Building Identification in which to specify what the building is being used for. For example, the evaluator can mention that the building is used as a restaurant in the "Use" portion of the form, and circle the occupancy class "Commercial". If the building does not relate to any of these classes, the use of the building can be mentioned in the Comments section.

2. Additional Designations

Besides occupancy classes, information pertaining to the building such as any historical aspect, a building being used for government services, and its use as an emergency shelter is also significant 
and may help in establishing priorities for the mitigation of issues.

- Historic. This aspect may be different for different communities. This information is significant since certain ordinances and codes may apply to such buildings.

- Government. All the buildings being used by local, federal and state governments for purposes other than the emergency are considered here.

- Shelter. It is particularly important to upgrade buildings that are predetermined as shelters for communities in case of emergencies or disasters. High priority is given to maintaining and improving these buildings.

While filling in the form, the occupancy section must be filled in consideration of these three points. It must be specified if the building is any of the three mentioned types. This means that if a school is predetermined to be a shelter, the form must be filled in such that the evaluator will circle school as well as the shelter option.

\section{Building Types Considered and Basic Scores}

The 17 types of buildings according to the FEMA P154 [5] RVS procedure are mentioned below. Each building type is followed by the specific alpha-numeric reference code (in brackets) used for it in the Data Collection Form.

- One- or multiple-story buildings with residential units with a light wood frame including singlefamily units as well as multiple-family units (W1).

- Multiple-story residential buildings with a minimum of 3000 square feet plan area per floor and with a light wood frame consisting of multiple units (W1A).

- Commercial and industrial buildings with a wood frame and a minimum area of 5,000 square feet per floor (W2).

- Steel moment-resisting frame buildings (S1).

- Braced steel frame buildings (S2).

- Light metal buildings (S3).

- Steel frame buildings with cast-in-place concrete shear walls (S4).

- Steel frame buildings with unreinforced masonry infill walls (S5).

- Concrete moment-resisting frame buildings (C1).

- Concrete shear-wall buildings (C2).

- Concrete frame buildings with unreinforced masonry infill walls (C3).

- Tilt-up buildings (PC1).

- Precast concrete frame buildings (PC2).

- Reinforced masonry buildings with flexible floor and roof diaphragms (RM1).

- Reinforced masonry buildings with rigid floor and roof diaphragms (RM2).

- Unreinforced masonry bearing-wall buildings (URM).

- Manufactured housing (MH).
Next, the Basic Score is calculated for each building type with the help of the damage and loss assessment functions. This score indicates the probability of collapse of the building if it experiences any extremely severe earthquake, known as risk-targeted maximum considered earthquake (MCER) ground motions. The Level 1 Data Collection Form has a space for mentioning the Basic Scores. The scores differ on the basis of the seismicity region. Different scores are obtained for Very High, High, Moderately High, Moderate, and Low seismicity regions.

In the pre-planning phase, some buildings are found to be constructed after the enforcement of the seismic codes but prior to the codes' enhancement in regions with very high or high or moderately high or moderate seismic intensity. These are the buildings constructed before the benchmark year. For such buildings the Basic Scores can be used. The pre-planning phase clearly specifies that in the case of a low seismicity region, Basic Scores are not applicable to buildings that were constructed after the corresponding benchmark year. However, the pre-planning phase fails to determine the years when the enforcement of seismic codes took place and the year of their enhancement and modification. Score Modifiers are included as a special feature in the Level 1 Data Collection Form and can be employed to modify the Basic Score depending on the date of construction of the building

\section{Score Modifiers}

After determining the building type through the completion of half of the Level 1 Data Collection Form, the next step is to evaluate the RVS score of the building with the help of a scoring matrix. As shown in Figure 2, the Basic Score as well as the Score Modifiers associated with the attributes that affect the seismic performance of buildings are included in the scoring matrix. Higher scores reflect the attributes that have a positive impact on the seismic performance of buildings since these attributes are associated with positive Score Modifiers. Conversely, lower scores reflect attributes that have an adverse impact on the seismic performance of buildings since these attributes are associated with negative Score Modifiers.

Each building type is affected to a different extent by the impact of its performance attributes on its structural performance; this implies that the building type determines the allocated Score Modifiers. If the specific performance attribute is irrelevant to a building type then the Score Modifier is represented by N/A, standing for not applicable. The scoring matrix in the Level 1 Data Collection Form mentions the Score Modifier associated with each attribute. 
The evaluator marks the associated Score Modifiers for the evaluated building by circling the reference code for the building type determined on the basis of FEMA P-154 [5]. The correct application of Score Modifiers can be ensured by adhering to the points given below.

1. Vertical Irregularity. The evaluator has to circle the Severe Vertical Irregularity Score Modifier in the Irregularities section of the form if single or multiple severe vertical irregularities are seen. However, if vertical irregularities of a moderate nature are seen, the evaluator is required to circle the Moderate Vertical Irregularity Score Modifier.

2. Plan Irregularity. The evaluator has to circle the Plan Irregularity Score Modifier in the Irregularities section of the form if single or multiple plan irregularities are seen.

3. Pre-Code. For buildings that were designed and built before the enforcement of seismic codes relevant to their building type, the Pre-Code Score Modifier will be applied during their evaluation process. The evaluator must focus on the year(s) of enforcement of seismic codes for various building types in the pre-planning phase. If the construction dates back to a period prior to the year of enforcement of seismic codes, then the evaluator will use the Pre-Code Score Modifier. Buildings situated in regions of low seismicity will not need this Score Modifier due to the procedure involved in the computation of Basic Scores.

4. Post-Benchmark. The evaluator applies this code if the evaluated building was designed after the local jurisdiction's enforcement of enhanced seismic codes for that specific building type. The year of enforcement of these improved codes is referred to as the benchmark year. The evaluator must focus on the benchmark year(s) for various building types in the pre-planning phase. If the year of construction is similar to the benchmark year or comes after the benchmark year, then a PostBenchmark Score Modifier is applied.

5. Soil Type. These Score Modifiers apply to Soil Types A, B, and E. If the soil type section in the form mentions the soil type to be Type A or B, then the evaluator circles the Soil Type A or B Score Modifier. If soil type $\mathrm{E}$ is mentioned in the form for a building with a maximum of three (3) stories, the evaluator circles the Soil Type E (1-3 stories) Score Modifier. If Soil Type $\mathrm{E}$ is identified for a building with more than three (3) stories, the evaluator circles the Soil Type E ( $>3$ stories) Score Modifier. The computation for Basic Scores involved the assumption of Soil Type CD (the average of Soil Type C and D). In such a case, no Score Modifier will be applied. In the case of Soil Type F, no score modifier can be applied since such buildings cannot be successfully evaluated through the RVS procedure.

6. Minimum Score, SMIN. Calculations of the probability of collapse of buildings with reference to a single condition led to the development of Individual Score Modifiers. When multiple score modifiers are added, they result in an exaggerated effect of the combination of multiple conditions, leading to a negative final score which means a probability of collapse greater than $100 \%$, which is impossible. The Minimum Score, SMIN, was devised to counter this problem. The worst standards for each of the parameters of soil type, irregularities (both vertical and plan), and building age are combined to yield the Minimum Score.

\section{Case Study}

The majority of buildings in Indonesia are reinforced concrete framed buildings. These buildings are designed in such a way that they can only show resistance to gravity loads. However, educational facility buildings of this type failed to resist the Yogyakarta earthquake that hit Indonesia on May 27, 2016. A total of 2155 educational facility buildings in the region suffered heavy damage and most of them collapsed as a result of the earthquake. The earthquake hit the Bantul district most violently, destroying 949 educational facility buildings, which accounted for $90 \%$ of the total such buildings. 752 buildings were destroyed in Central Java. The area mostly severely affected was the Klaten district, where 64 buildings were affected and 257 buildings were heavily affected, accounting for $38 \%$ of the buildings in the entire district [17].

This study uses the RVS technique to determine the Final Level 1 Score, SL1 for the buildings being evaluated, which are the educational facility buildings of Jenderal Soedirman University, Indonesia in this case. Figure 3 shows the nine buildings situated in Purwokerto and Purbalingga which are evaluated using the RVS technique. This study assumes the seismicity level of these structures to be moderately high. The soil type is taken to be stiff and the building type is assumed to be Type $\mathrm{C} 1$ (moment-resisting frame) and Type C3 (buildings composed of a concrete frame with unreinforced stone infill wall structures). The irregularities, either plan or vertical, are not taken into consideration. Moreover, the pounding of buildings is also not considered. Hence, the study is limited to the use of Level 1 of the FEMA P-154 [5] score modifier only. 


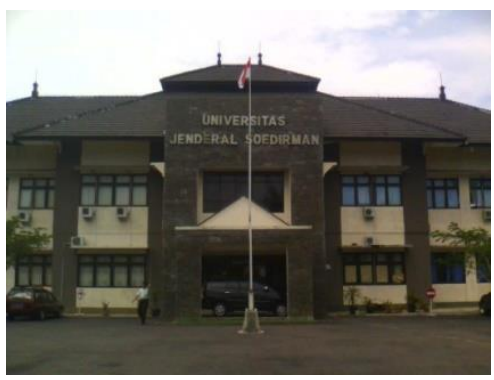

a. Building A Faculty of Engineering (A)

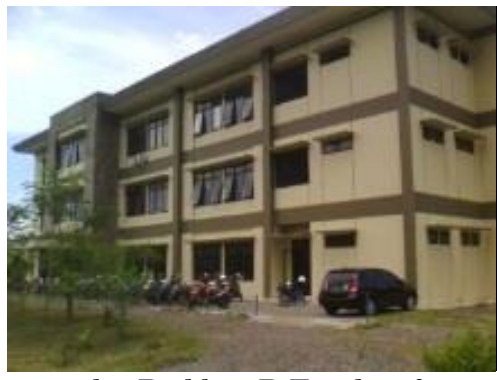

d. Building D Faculty of Engineering (D)

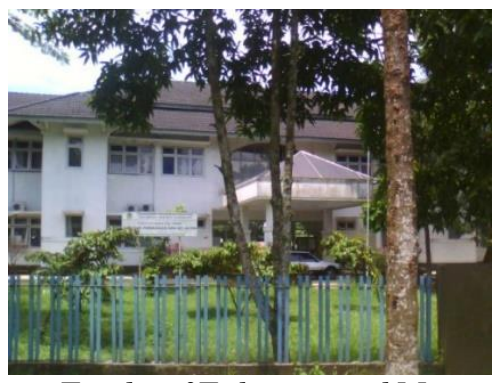

g. Faculty of Fishesries and Marine Science (G)

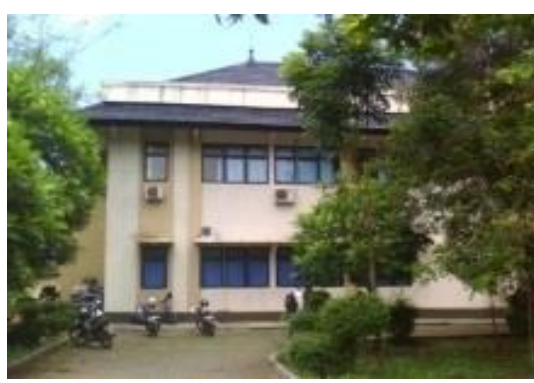

b. Building B Faculty of Engineering

(B)

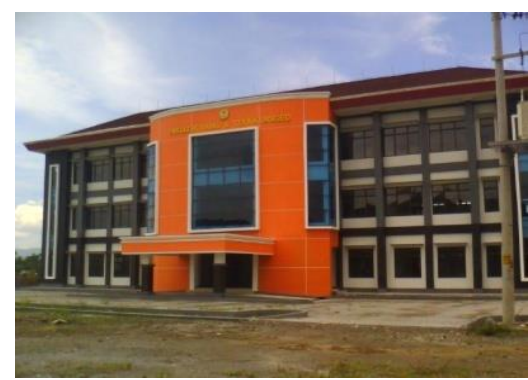

e. Building E Faculty of Engineering

(E)

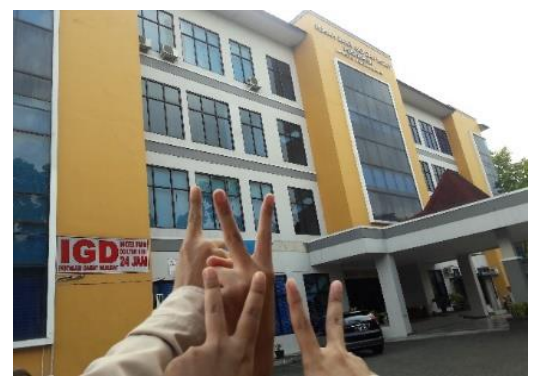

h. The Oral and Dental Hospital (H)

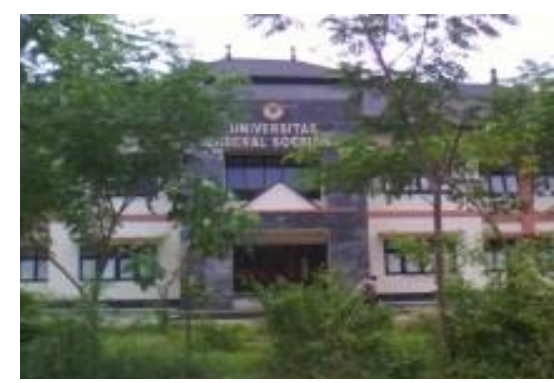

c. Building C Faculty of Engineering

(C)

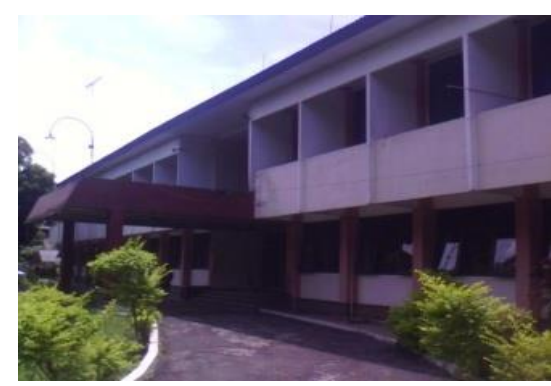

f. Faculty of Mathematic and Natural Science (F)

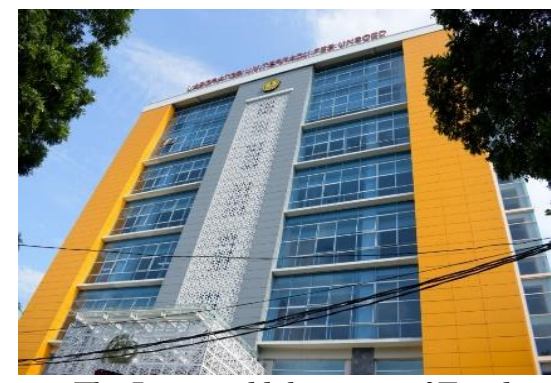

i. The Interated laboratory of Faculty of Economics and Business (I)

Figure 3. Assessed Educational Facility Buildings of Jenderal Soedirman University

\section{Results and Discussion}

In this study, the visual pavement survey technique was used along with a Data Collection Form in the RVS procedure to assess the buildings. The form is filled in by the evaluator or screening personnel with data collected through visual observation of the building from the exterior, and if possible, the interior. Figure 2 shows the Level 1 Data Collection Form which has spaces for inserting data such as the building identification number (BIN), building occupation class, images and drawings of the building, and data about the seismic performance of the building. After inserting the data in the form, the evaluator computes a score that represents the building's expected seismic performance.

To fill in the Data Collection Form, the evaluator begins with an examination of the building's structural materials as well as the basic structural seismic force-resisting system. The form offers different options of Basic Scores for different building types. The evaluator has to determine the correct building type and circle the right option, then finds and circles Score Modifiers to modify the Basic Score. The Score Modifiers associated with the building's performance attributes give a score that is added to or subtracted from the Basic Score to give the Final Score, denoted by $S_{L 1}$. Hence the value $S_{L 1}$ for a building is given as the selected Score Modifiers +/- Basic Score. The final score obtained in this way is compared with the minimum score, which is denoted by $S_{M I N}$. If $S_{M I N}$ exceeds the final score, the former is applied. The values of the Final Level 1 Score usually lie between 0 and 7. Higher final scores imply that the building's probable seismic performance is good and that the building is highly resistant to collapse. The final scores of the educational facility buildings evaluated at Jenderal Soedirman University are tabulated in Table 1. 
Table 1. Determination of Final Scores (level 1) from Data Collection Forms

\begin{tabular}{|c|c|c|c|c|c|c|c|c|c|}
\hline \multirow{2}{*}{ Parameters } & \multicolumn{9}{|c|}{ Assessed educational facility buildings of Jenderal Soedirman University } \\
\hline & $\mathrm{A}$ & B & $\mathrm{C}$ & $\mathrm{D}$ & $\mathrm{E}$ & $\mathrm{F}$ & $\mathrm{G}$ & $\mathrm{H}$ & $\mathrm{I}$ \\
\hline Building type & $\mathrm{C} 1$ & $\mathrm{C} 1$ & $\mathrm{C} 1$ & $\mathrm{C} 1$ & $\mathrm{C} 1$ & $\mathrm{C} 1$ & $\mathrm{C} 1$ & C3 & C3 \\
\hline Basic score & 1.7 & 1.7 & 1.7 & 1.7 & 1.7 & 1.7 & 1.7 & 1.4 & 1.4 \\
\hline Severe vertical irregularity & -1.0 & -1.0 & -1.0 & -1.0 & -1.0 & -1.0 & -1.0 & -0.8 & -0.8 \\
\hline Moderate vertical irregularity & -0.6 & -0.6 & -0.6 & -0.6 & -0.6 & -0.6 & -0.6 & -0.5 & -0.5 \\
\hline Plan irregularity & -0.7 & -0.7 & -0.7 & -0.7 & -0.7 & -0.7 & -0.7 & -0.6 & -0.6 \\
\hline Pre-code & -0.4 & -0.4 & -0.4 & -0.4 & $\overline{-0.4}$ & -0.4 & -0.4 & -0.1 & -0.1 \\
\hline Post-benchmark & 1.9 & 1.9 & 1.9 & 1.9 & 1.9 & 1.9 & 1.9 & NA & NA \\
\hline Hard rock soil & 0.6 & 0.6 & 0.6 & 0.6 & 0.6 & 0.6 & 0.6 & 0.7 & 0.7 \\
\hline Soft soil (1-3 stories) & -0.2 & -0.2 & -0.2 & -0.2 & -0.2 & -0.2 & -0.2 & -0.4 & -0.4 \\
\hline Soft soil (>3 stories) & -0.6 & -0.6 & -0.6 & -0.6 & -0.6 & -0.6 & -0.6 & -0.4 & -0.4 \\
\hline Minimum score & 0.3 & 0.3 & 0.3 & 0.3 & 0.3 & 0.3 & 0.3 & 0.3 & 0.3 \\
\hline Final score & 0.6 & 0.6 & 0.6 & 0.6 & 0.3 & 0.6 & 0.6 & 0.3 & 1.4 \\
\hline
\end{tabular}

C1 moment-resisting frame

C3 concrete frame with unreinforced masonry infill walls

Since the educational facility buildings evaluated at Jenderal Soedirman University are of Type C1 (moment-resisting frame) and Type C3 (buildings with a concrete frame with unreinforced masonry infill wall structures), their basic scores are 1.7 and 1.4 respectively. Both these scores obtained through the RVS evaluation technique add up to yield the final level 1 score denoted by $S_{L 1}$, which are given as follows;

$S_{L 1}=+0.3$ (building E, H), +0.6 (building A, B, C, D, F, G) and +1.4 (building I)

Ovreall, these scores indicate the probability of collapse of the building in the event that it experiences ground motions equal to or greater in magnitude than the maximum considered earthquake targeted risk $\left(\mathrm{MCE}_{\mathrm{R}}\right)$. For instance, an $\mathrm{S}_{\mathrm{L} 1}$ score of +0.3 indicates that the probability of building collapse is equal to $10^{0.3}$ in the event of seismic motions. The probability of collapse computed is not absolute and is just an estimate as these scores are computed on the basis of limited observed and analytical data.

\section{Conclusions}

The RVS technique helped in the identification and evaluation of buildings that are vulnerable to seismic threats. The RVS technique offers various benefits such as allowing the evaluation to be performed by any individual, without the need for a structural engineer. This technique involves minimum uncertainty and allows outcomes to be determined by screeners or evaluators. Buildings that are evaluated as being hazardous and vulnerable to seismic dangers are then further evaluated by professional designers who are expert in structural design. This was the case with the nine buildings of Jenderal Soedirman University that were evaluated in this study. The RVS technique imparts useful multi-purpose information that may be used for (1) assessing the seismic retrofitting requirements of a community or organization; (2) devising plans for the mitigation of seismic hazards; (3) using buildings as examples for studying the impacts of seismic motion and for the evaluation of losses caused by these disasters; (4) devising plans for making efforts aimed at the evaluation of a building's post-earthquake safety; and (5) collecting data pertaining to the seismic vulnerability of each building, which will be helpful for multiple purposes including insurance rating, decisions made at the time of transfer of ownership rights of a building, and for remodeling that may be needed in the permitting process.

\section{Acknowledgments}

The authors thank Jenderal Soedirman University for funding, along with Taiwan Ministry of Education (MOE) for the PhD fellowship. The authors also thank Esya Alfidiah for providing assistance in accomplishing the goal of this study.

\section{References}

1. ASCE/SEI 41-13, Seismic Evaluation and Retrofit of Existing Buildings, American Society of Civil Engineers, USA, 2014.

2. El-Betar S.A., Seismic Vulnerability Evaluation of Existing R.C. Buildings, HBRC Journal, 14, 2018, pp. 189-197.

3. Aftabur, R.M. and Shajib, U.M., Seismic Vulnerability Assessment of RC Structures: A Review, International Journal of Science and Emerging Technologies, 4(4), 2012, pp. 171-177.

4. Bahar, I., Effendi, I., Putranto, E.T., and Sukarna, D., Earthquake Monitoring in Indonesia, Islamic Educational, Scientific and Cultural Organization (ISESCO), Rabat, Morocco, 1997.

5. FEMA P-154, Rapid Visual Screening of Buildings for Potential Seismic Hazards: A Handbook, Federal Emergency Management Agency (FEMA), Washington DC, USA, 2015. 
6. Sarmah, T. and Das, S., Earthquake Vulnerability Assessment for RCC Buildings of Guwahati City using Rapid Visual Screening, Procedia Engineering, 212, 2018, pp. 214-221.

7. Lang, K., Seismic Vulnerability of Existing Buildings, Federal Institute of Technology (ETH), Zurich, Switzerland, 2002.

8. IS 13935, Indian Standard Guidelines for Repair and Seismic Strengthening of Buildings, Bureau of Indian Standards (BIS), New Delhi, India, 2009.

9. Jain, S.K., Mitra, K., Kumar, M., and Shah, M., A Proposed Rapid Visual Screening Procedure for Seismic Evaluation of RC-Frame Buildings in India, Earthquake Spectra, 26, 2010, pp. 709-729.

10. Japan Building Disaster Prevention Association (JDBPA), Seismic Evaluation and Retrofit, Tokyo, Japan, 2001.

11. IRC-NRC: Institute for Research in Construction, National Research Council of Canada (NRCC), Manual for Screening of Buildings for Seismic Investigation, Ottawa, Canada, 1993.

12. Achs, G. and Adam, C., A Rapid Visual Screening Methodology for the Seismic Vulnerability Assessment of Historic Brick Masonry Buildings in Vienna, Proceedings of 15WCEE: World Conference on Earthquake Engineering, Lisbon, Portugal, September 24-28, 2012.

13. Rajarathnam, S. and Santhakumar, A.R., Assessment of Seismic Building Vulnerability Based on Rapid Visual Screening Technique Aided by Aerial Photographs on a GIS Platform, Natural Hazards Journal, 78(2), 2015, pp. 779802.

14. Moseley, J. and Dritsos, S., Next Generation Rapid Visual Screening for RC Buildings to Assess Earthquake Resilience, Proceedings of 17th International Conference on Concrete Structures, Thessaloniki, Greece, 2016.

15. Ningthoujam, M.C. and Nanda, R.P., Rapid Visual Screening Procedure of Existing Building Based on Statistical Analysis, International Journal of Disaster Risk Reduction, 28, 2018, pp. 720-730.

16. Perrone, D., Aiello, M.A., Pecce, M., and Rossi, F., Rapid Visual Screening for Seismic Evaluation of RC Hospital Buildings, Structures, 3, 2015, pp. 57-70.

17. Elnashai, A.S., Kim, S.J., Yun, G.J., and Sidarta, D., The Yogyakarta Earthquake of May 27, 2006 , Mid-America Earthquake Center, University of Illinois at Urbana-Champaign, USA, 2006. 